\title{
MATHEMATICAL MODELING DIFFUSION OF ADMIXTURE PARTICLES IN A STRIP WITH RANDOMLY LOCATED SPHERICAL INCLUSIONS OF DIFFERENT MATERIALS WITH COMMENSURABLE VOLUME FRACTIONS OF PHASES
}

\section{Olha Chernukha $^{1,2}$; Yurii Bilushchak ${ }^{1,2}$; Anastasiia Chuchvara ${ }^{1}$}

\author{
${ }^{1}$ Center of Mathematical Modelling within Ya.S.Pidstryhach Institute of Applied \\ Problems of Mechanics and Mathematics of the NAS of Ukraine, Lviv, Ukraine \\ ${ }^{2}$ Lviv Polytechnic National University, Lviv, Ukraine
}

\begin{abstract}
Summary. The process of diffusion of admixture particles in a multiphase randomly nonhomogeneous body with spherical inclusions of different materials with commensurable volume fractions of phases is investigated. According to the theory of binary systems, a mathematical model of admixture diffusion in a multiphase body with spherical randomly disposed inclusions of different radii is constructed. The dense packing of spheres with different radii is used to modeling the skeleton of the body. The contact initial-boundary value problem is reduced to the mass transfer equation for the whole body. Its solution is constructed in the form of Neumann series. On the basis of the obtained calculation formula, a quantitative analysis of the mass transfer of admixture in the body with spherical inclusions, which are filled with materials of fundamentally different physical nature, but commensurable volume fractions, is carried out. It is shown that in modeling skeleton by spheres of one characteristic radius averaged concentration values coincide for different cases of radius, such as when characteristic radius equals to the average value of the radii of inclusions; or to the radius corresponding the smallest spherical inclusion; or to the radius of an order of magnitude smaller than this value.

Key words: mathematical modeling, multiphase stochastic structure, spherical inclusion, admixture concentration, dense packing of spheres, averaging over the ensemble of phase configurations, computing.
\end{abstract}

Statement of the problem. Research and control of mass transfer properties in structures with a complex internal structure play an important role in the manufacture of composite materials, catalysts, membranes, industrial adsorbents, predicting and researching the spread of pollution in objects of the natural environment $[1,2]$. This is due primarily to the fact, that the presence of internal nonhomogeneities, in particular, in the form of spherical inclusions (in the form of pores or grains) in the structure, has a significant effect on the chemical and physical interaction of solids with gases and liquids. At the same time, the pore space, as a rule, is modeled in the form of a random structure [3], while the physical characteristics and sizes of nonhomogeneities in it can be different, which makes it necessary to consider the medium as multiphase one.

Analysis of the available investigations. There are various approaches to modeling physical processes in structures with internal nonhomogeneities depending on the specific properties that should be investigated. In particular, if the velocity field is known, the random walk method is simple to implement to study the phenomenon of diffusion $[4,5]$. The latticeBoltzmann method has become widely used in recent years. Thus, in the paper [6] this method was applied to solve the diffusion equation in porous medium which was modeled by twodimensional Voronoi diagrams. The study [7] deals with a combination of lattice-Boltzmann and random walk methods, which was used to track the motion of particles in a body with structural nonhomogeneities generated by the Monte-Carlo and Jodrey-Tory methods. Along 
with many advantages of the lattice-Boltzmann method, it is worth noting that its implementation requires significant computer performance, and its use on moving boundaries and for multiphase or multicomponent models is complicated. Besides, in practice structures with internal nonhomogeneities are characterized by a concentration function jump of the admixture substance at the boundaries of phase contact, whereas nonideal contact conditions are not imposed in the works reviewed, that are certain simplification of the corresponding mathematical model.

An approach to the mathematical description of mass transfer processes in multiphase randomly nonhomogeneous media, based on the construction of a solution in the form of Neumann integral series and its further averaging over an ensemble of phase configurations, while explicitly taking into account the jump of the concentration function and the equality of fluxes on random phase boundaries, is proposed in papers [8-10].

The Objective of the work is to investigate the process of migration of admixture substance in a multiphase body with randomly located spherical inclusions of different materials under the condition of commensurable volume fractions of phases and to establish the main regularities of the distributions of the random field of admixture concentration on the basis of the developed approach [8].

Formulation of the problem. Consider the migration of admixture particles in the stochastic nonhomogeneous layer of thickness $z_{0}$ that contains of $N+1$ phases of different density, in which the diffusion coefficients of admixture particles can differ significantly, but are constant within each phase. We assume that the volume fraction of none of the phases is dominant, that is, in the medium the basic phase cannot be separated. The coordinates of all simply connected domains are unknown. At the same time, we accept that the spherical inclusions in the body disposed under the uniform distribution and they are located completely inside the domain of the body. Respectively, on its outer surfaces one of the phases, namely the skeleton, is placed. Consider that one or several characteristic radii of inclusions of one phase can be singled out, and the radii of spheres of different phases can be either different or coincide, in particular, for some materials. Moreover, if there are several characteristic radii of spherical inclusions of the same material, we shall consider such spheres as different phases, but with the same diffusion coefficients and density.

If a convective mechanism is absent, the process of mass transfer of the admixture substance in such body is described by the diffusion equations for each phase $k(k=\overline{0, N})$ :

$$
\rho_{k} \frac{\partial c_{k}(\vec{r}, t)}{\partial t}=d_{k}\left[\frac{\partial^{2} c_{k}(\vec{r}, t)}{\partial x^{2}}+\frac{\partial^{2} c_{k}(\vec{r}, t)}{\partial y^{2}}+\frac{\partial^{2} c_{k}(\vec{r}, t)}{\partial z^{2}}\right], \vec{r} \in\left(V^{(k)}\right), t \in[0 ; \tau](\tau<\infty),
$$

where $c_{k}(\vec{r}, t)$ is the concentration of the admixture substance in the $k$ th phase; $\rho_{k}$ is the density of the $k$ th phase; $d_{k}$ is the kinetic coefficient of transfer of the migrating substance in $k$ th phase $\left(d_{k}=D_{k} \rho_{k}, D_{k}\right.$ is the diffusion coefficient of particles in the $k$ th phase); $\vec{r}=(x, y, z)$ is a radius-vector of the running point; $t$ is the time.

In the notation used, $k=0$ corresponds to the material of the body skeleton, that is $c_{0}(\vec{r}, t)=c_{\text {skeleton }}(\vec{r}, t) ; k=j(j=\overline{1, N})$ corresponds to the spherical inclusion of different materials, and in the case of porous bodies to its porous components of different radii: $c_{j}(\vec{r}, t)=c_{j \text { pore }}(\vec{r}, t)$. Thus, spherical pores can be filled with air (gas), liquid, their mixture or vapor-gas mixture, however, with one substance within one phase, and their physical characteristics and geometric parameters are such that the condition of constancy of the coefficients in simply connected domains is satisfied. It is also possible to implement the case 
when part of the phases, for example $j=\overline{1, m}$, is inclusions (solid phase), the other part $j=\overline{m, N}$ is spherical pores of different radii and/or of different materials.

Let the admixture substance in the body be absent at the initial moment of time, at the upper boundary of the body $z=0$ a constant value of the admixture concentration $c_{*}$ is kept, and at the lower boundary it be equal to zero. Namely, the following conditions are given

$$
\begin{gathered}
\left.c_{0}(\vec{r}, t)\right|_{t=0}=\left.c_{j}(\vec{r}, t)\right|_{t=0}=0, j=\overline{1, N}, \\
\left.c_{0}(\vec{r}, t)\right|_{z=0}=c_{*} \equiv \text { const },\left.c_{0}(\vec{r}, t)\right|_{z=z_{0}}=0 ;\left.c_{k}(\vec{r}, t)\right|_{x, y \rightarrow \pm \infty} \leq K<\infty \quad(k=\overline{0, N}) .
\end{gathered}
$$

In addition, we assume the conditions of non-ideal contact for the concentration of the migrating substance at the boundaries of the phases contact [8], which are a consequence of the ideal contact conditions for the chemical potentials of admixture particles in these phases

$$
\begin{gathered}
\left.\kappa_{j} c_{j}(\vec{r}, t)\right|_{\vec{r} \in \Gamma_{j l}-0}=\left.\kappa_{l} c_{l}(\vec{r}, t)\right|_{\vec{r} \in \Gamma_{j l}+0}, \\
\left.\rho_{j} d_{j} \vec{\nabla} c_{j}(\vec{r}, t)\right|_{\vec{r} \in \Gamma_{j l}-0}=\left.\rho_{l} d_{l} \vec{\nabla} c_{l}(\vec{r}, t)\right|_{\vec{r} \in \Gamma_{j l}+0}, j, l=\overline{0, N}, j \neq l .
\end{gathered}
$$

Here $\kappa_{k}=A \gamma_{k}(k=\overline{0, N}) ; \gamma_{k}$ is the coefficient of activity; $\Gamma_{j l}$ is the interphase boundaries where the phases $j$ and $l$ are in contact [11, 12].

In order to model the skeleton of the body (matrix) with a dense packing of spheres, we use $M$ spheres of different radii $R_{m_{j}}(j=\overline{0, N}), \sum_{j=0}^{N} m_{j}=M$ (Fig. 1) [13]. In particular, $m_{0}$ different characteristic radii $\left(R_{1} \ldots R_{m_{0}}\right)$ are used for the skeleton (matrix), $m_{1}$ different radii ( $R_{m_{0}+1} \ldots R_{m_{0}+m_{1}}$ ) are used for spherical inclusions of the first phase, $m_{2}$ different radii ( $R_{m_{0}+m_{1}+1} \ldots R_{m_{0}+m_{1}+m_{2}}$ ) are used for spherical inclusions of the second phase, etc. Inclusions of the phase $N$ are modeled with $m_{N}$ different characteristic radii $\left(\boldsymbol{R}_{m_{0}+\ldots+m_{N-1}+1} \ldots \boldsymbol{R}_{m_{0}+\ldots+m_{N-1}+m_{N}}\right)$, here $R_{m_{0}+\ldots+m_{N-1}+m_{N}} \equiv \boldsymbol{R}_{M}$. We assume that two spheres of inclusion phases can be arbitrarily close, but at the same time a minimum amount of the skeleton material remains between them, that is, two spheres can touch, but the spherical inclusions cannot intersect. The sphere that belongs to the skeleton can contact with other spheres of the skeleton and/or with spheres of inclusions, moreover, they can have different radii. We consider the case when spheres of all radii, both the skeleton and pores, are distributed in the volume of the medium behind a uniform distribution. In what follows, we will consider spheres of different (but characteristic) sizes as different phases. 

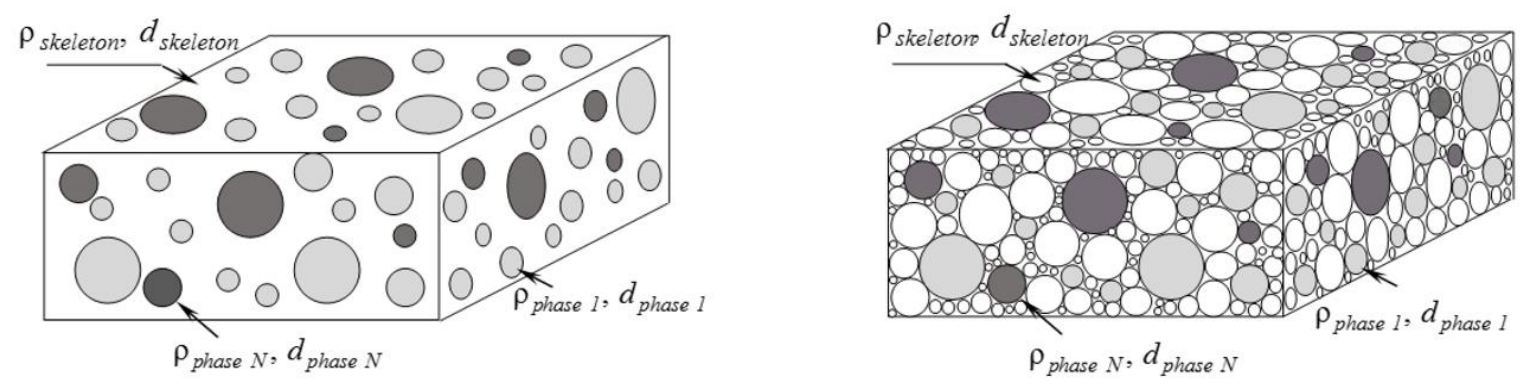

Figure 1. Modeling an element of the multiphase body with spherical inclusions by dense packing of spheres

Note that at the boundaries of spheres, which simulate the skeleton of the body $\left(l={\overline{1 ; m_{0}}}\right)$ and do not contact spheres of the phases of inclusions, there are no jump discontinuities of the concentration function and of its derivative, then

$$
\begin{gathered}
\left.\kappa_{0} c_{i}(\vec{r}, t)\right|_{\vec{r} \in \Gamma-0}=\left.\kappa_{0} c_{i+1}(\vec{r}, t)\right|_{\vec{r} \in \Gamma+0} \quad\left(i=\overline{1 ; m_{0}-1}\right) ; \\
\left.\rho_{0} d_{0} \vec{\nabla} c_{i}(\vec{r}, t)\right|_{\vec{r} \in \Gamma-0}=\left.\rho_{0} d_{0} \vec{\nabla} c_{i+1}(\vec{r}, t)\right|_{\vec{r} \in \Gamma+0} \quad\left(i=\overline{1 ; m_{0}-1}\right) .
\end{gathered}
$$

For spheres that correspond to the phases of inclusions and are in contact only with each other within one phase, we have:

$$
\begin{gathered}
\left.\kappa_{1} c_{i}(\vec{r}, t)\right|_{\vec{r} \in \Gamma-0}=\left.\kappa_{1} c_{i+1}(\vec{r}, t)\right|_{\vec{r} \in \Gamma+0} \quad\left(i=\overline{m_{0}+1 ; m_{0}+m_{1}-1}\right) ; \\
\left.\rho_{1} d_{1} \vec{\nabla} c_{i}(\vec{r}, t)\right|_{\vec{r} \in \Gamma-0}=\left.\rho_{1} d_{1} \vec{\nabla} c_{i+1}(\vec{r}, t)\right|_{\vec{r} \in \Gamma+0} \quad\left(i=\overline{m_{0}+1 ; m_{0}+m_{1}-1}\right), \\
\left.\kappa_{2} c_{i}(\vec{r}, t)\right|_{\vec{r} \in \Gamma-0}=\left.\kappa_{2} c_{i+1}(\vec{r}, t)\right|_{\vec{r} \in \Gamma+0} \quad\left(i=\overline{m_{0}+m_{1}+1 ; m_{0}+m_{1}+m_{2}-1}\right) ; \\
\left.\rho_{2} d_{2} \vec{\nabla} c_{i}(\vec{r}, t)\right|_{\vec{r} \in \Gamma-0}=\left.\rho_{2} d_{2} \vec{\nabla} c_{i+1}(\vec{r}, t)\right|_{\vec{r} \in \Gamma+0}\left(i=\overline{m_{0}+m_{1}+1 ; m_{0}+m_{1}+m_{2}-1}\right), \\
\left.\kappa_{N} c_{i}(\vec{r}, t)\right|_{\vec{r} \in \Gamma-0}=\left.\kappa_{N} c_{i+1}(\vec{r}, t)\right|_{\vec{r} \in \Gamma+0} \quad\left(i=\overline{m_{0}+\ldots+m_{N-1}+1 ; M-1}\right) ; \\
\left.\rho_{N} d_{N} \vec{\nabla} c_{i}(\vec{r}, t)\right|_{\vec{r} \in \Gamma-0}=\left.\rho_{N} d_{N} \vec{\nabla} c_{i+1}(\vec{r}, t)\right|_{\vec{r} \in \Gamma+0} \quad\left(i=\overline{m_{0}+\ldots+m_{N-1}+1 ; M-1}\right) .
\end{gathered}
$$

That is, in the general case $(j=\overline{1 ; N})$ we can write the contact condition for spheres of one phase in the form

$$
\left.\kappa_{j} c_{i}(\vec{r}, t)\right|_{\vec{r} \in \Gamma-0}=\left.\kappa_{j} c_{i+1}(\vec{r}, t)\right|_{\vec{r} \in \Gamma+0}\left(i=\overline{\sum_{k=0}^{j-1} m_{k}+1 ; \sum_{k=0}^{j} m_{k}}\right) ;
$$




$$
\left.\rho_{j} d_{j} \vec{\nabla} c_{i}(\vec{r}, t)\right|_{\vec{r} \in \Gamma-0}=\left.\rho_{j} d_{j} \vec{\nabla} c_{i+1}(\vec{r}, t)\right|_{\vec{r} \in \Gamma+0}\left(i=\overline{\sum_{k=0}^{j-1} m_{k}+1 ; \sum_{k=0}^{j} m_{k}}\right),
$$

whence

$$
\left.c_{i}(\vec{r}, t)\right|_{\vec{r} \in \Gamma-0}=\left.c_{i+1}(\vec{r}, t)\right|_{\vec{r} \in \Gamma+0},\left.\quad \vec{\nabla} c_{i}(\vec{r}, t)\right|_{\vec{r} \in \Gamma-0}=\left.\vec{\nabla} c_{i+1}(\vec{r}, t)\right|_{\vec{r} \in \Gamma+0}\left(i=\overline{m_{0}+1 ; M-1}\right) .
$$

Then, taking into account the contact interaction between the different phases, the conditions of nonideal contact (4)-(5) for the concentration function will take the form

$$
\begin{gathered}
\left.\kappa_{j} c_{j}(\vec{r}, t)\right|_{\vec{r} \in \Gamma_{j l}-0}=\left.\kappa_{l} c_{l}(\vec{r}, t)\right|_{\vec{r} \in \Gamma_{j l}+0}, \quad j, l=\overline{1 ; M} ; \\
\left.\rho_{j} d_{j} \vec{\nabla} c_{j}(\vec{r}, t)\right|_{\vec{r} \in \Gamma j l-0}=\left.\rho_{l} d_{l} \vec{\nabla} c_{l}(\vec{r}, t)\right|_{\vec{r} \in \Gamma_{j l}+0}, j, l=\overline{1 ; M},
\end{gathered}
$$

here $\Gamma_{j l}$ are the sections of interphase boundaries where phases $j$ and $l$ are in contact. Note that the case $j=l$ is taken into account here, that is, the case of contact interaction of spheres of the same phase.

In the case when inclusions are in contact only with the matrix, conditions (6) - (7) can be written as

$$
\begin{gathered}
\left.\kappa_{l} c_{l}(\vec{r}, t)\right|_{\vec{r} \in \Gamma_{l p_{j}}-0}=\left.\kappa_{p_{j}} c_{p_{j}}(\vec{r}, t)\right|_{\vec{r} \in \Gamma_{l p_{j}}+0}, \\
\left.\rho_{l} d_{l} \vec{\nabla} c_{l}(\vec{r}, t)\right|_{\vec{r} \in \Gamma_{l p_{j}}-0}=\left.\rho_{p_{j}} d_{p_{j}} \vec{\nabla} c_{p_{j}}(\vec{r}, t)\right|_{\vec{r} \in \Gamma_{l p_{j}}+0}, \\
\left.\kappa_{p_{j}} c_{p_{j}}(\vec{r}, t)\right|_{\vec{r} \in \Gamma_{l p_{j}}-0}=\left.\kappa_{l} c_{l}(\vec{r}, t)\right|_{\vec{r} \in \Gamma_{l p_{j}}+0}, \\
\left.\rho_{p_{j}} d_{p_{j}} \vec{\nabla} c_{p_{j}}(\vec{r}, t)\right|_{\vec{r} \in \Gamma_{l p_{j}}-0}=\left.\rho_{l} d_{l} \vec{\nabla} c_{l}(\vec{r}, t)\right|_{\vec{r} \in \Gamma_{l p_{j}}+0} \\
\text { Here } l=\overline{1, m}_{0} ; p_{j}=\sum_{k=0}^{j-1} m_{k}+1 ; \sum_{k=0}^{j} m_{k}, j=\overline{1 ; N} .
\end{gathered}
$$

Solving the contact initial-boundary value problem. We reduce the contact problem of diffusion (1), (8)-(11) to the diffusion equation for the whole body. For this purpose, we take into consideration a random function of the spatial coordinate $c(\vec{r}, t)$, which describes the concentration in the whole body: 


$$
c(\vec{r}, t)=\left\{\begin{array}{l}
c_{j}(\vec{r}, t), \quad \vec{r} \in\left(V_{j}\right), j=\overline{1, M} \\
\text { satisfies conditions (8)-(11), } \vec{r} \in \Gamma_{p_{j}}, p_{j}=\overline{\sum_{k=0}^{j-1} m_{k}+1 ; \sum_{k=0}^{j} m_{k}, j=\overline{1, N}} .
\end{array}\right.
$$

Here $V_{j}$ is the volume of the phase $j$ (multiconnected domain).

Using a random operator (the structure function) $\eta_{i j}(\vec{r})=\left\{\begin{array}{ll}1, & \vec{r} \in\left(V_{j}\right), \\ 0, & \vec{r} \notin\left(V_{j}\right),\end{array}\right.$ [14] for $j=\overline{1 ; M}$, we can represent the diffusion coefficient $d(\vec{r})=\left\{\begin{array}{ll}d_{j}, & \vec{r} \in\left(V_{j}\right), \\ 0, & \vec{r} \notin\left(V_{j}\right),\end{array}\right.$ and the density coefficient $\rho(\vec{r})=\left\{\begin{array}{ll}\rho_{j}, & \vec{r} \in\left(V_{j}\right), \\ 0, & \vec{r} \notin\left(V_{j}\right),\end{array}\right.$ in the form

$$
d(\vec{r})=\sum_{j=1}^{M} \sum_{i=1}^{n_{j}} d_{j} \eta_{i j}(\vec{r}), \quad \rho(\vec{r})=\sum_{j=1}^{M} \sum_{i=1}^{n_{j}} \rho_{j} \eta_{i j}(\vec{r})
$$

Considering that the function $c(\vec{r}, t)$ has discontinuities of the first kind we have

$$
\vec{\nabla} c(\vec{r}, t)=\{\vec{\nabla} c(\vec{r}, t)\}+[c(\vec{r}, t)]_{\Gamma_{p_{j}}} \delta\left(\vec{r}-\vec{r}_{\Gamma_{p_{j}}}\right)
$$

and the value $\Delta c(\vec{r}, t)$ is found as

$$
\Delta c(\vec{r}, t)=\{\Delta c(\vec{r}, t)\}+[\vec{\nabla} c(\vec{r}, t)]_{\Gamma_{p_{j}}} \delta\left(\vec{r}-\vec{r}_{\Gamma_{p_{j}}}\right)+[c(\vec{r}, t)]_{\Gamma_{p_{j}}} \vec{\nabla} \delta\left(\vec{r}-\vec{r}_{\Gamma_{p_{j}}}\right) .
$$

Here $\vec{r}_{\Gamma_{p_{j}}}$ is the radius-vector of points of the boundary $\Gamma_{p_{j}} ;\{\ldots\}$ are the domains of continuity of the function; $[\ldots]_{\Gamma_{p_{j}}}$ is the jump of the function on the boundary $\Gamma_{p_{j}}$, $p_{j}=\overline{\sum_{k=0}^{j-1} m_{k}+1 ; \sum_{k=0}^{j} m_{k}}, j=\overline{1 ; N}$, and it differs from zero only if spheres of different material are in contact; $\delta(\vec{r})$ is Dirac delta function.

The coefficients of the problem are constant in the limits of each phase, and the coefficient $d(\vec{r})$ is a piecewise constant function and has discontinuities of the first kind on the contact boundaries, then

$$
\vec{\nabla} d(\vec{r})=[d(\vec{r})]_{\vec{r} \in \Gamma_{p_{j}}} \delta\left(\vec{r}-\vec{r}_{\Gamma_{p_{j}}}\right) .
$$

Since the equation of mass balance is satisfied for the whole body, using the expression for the admixture flux, we can present the diffusion equation for the body as a whole in the form 


$$
\rho(\vec{r}) \frac{\partial c(\vec{r}, t)}{\partial t}=\vec{\nabla} d(\vec{r}) \vec{\nabla} c(\vec{r}, t)+d(\vec{r}) \Delta c(\vec{r}, t) .
$$

Then, taking into account relations (13)-(15), expression (16) can be represented as

$$
\begin{gathered}
\rho(\vec{r}) \frac{\partial c(\vec{r}, t)}{\partial t}=\{d(\vec{r})\}\{\Delta c(\vec{r}, t)\}+[d(\vec{r})]_{\Gamma_{p_{j}}}[\vec{\nabla} c(\vec{r}, t)]_{\Gamma_{p_{j}}} \delta\left(\vec{r}-\vec{r}_{\Gamma_{p_{j}}}\right)+ \\
+[d(\vec{r})]_{\Gamma_{p_{j}}}[c(\vec{r}, t)]_{\Gamma_{p_{j}}} \vec{\nabla} \delta\left(\vec{r}-\vec{r}_{\Gamma_{p_{j}}}\right)+[d(\vec{r})]_{\Gamma_{p_{j}}}[c(\vec{r}, t)]_{\Gamma_{p_{j}}} \delta^{2}\left(\vec{r}-\vec{r}_{\Gamma_{p_{j}}}\right) .
\end{gathered}
$$

Here $p_{j}=\overline{\sum_{k=0}^{j-1} m_{k}+1 ; \sum_{k=0}^{j} m_{k}}, j=\overline{1 ; N}$.

By using the representation of the characteristics of the medium (12) and the condition of continuity of the body, equation (17) can be written in the form

$$
L(\vec{r}, t) c(\vec{r}, t)=\sum_{j=1}^{M} \sum_{i=1}^{n_{j}} L_{i j}(\vec{r}, t) c(\vec{r}, t)=0
$$

where in the general case

$$
\begin{gathered}
L_{i j}(\vec{r}, t)=\rho_{j} \eta_{i j}(\vec{r}) \frac{\partial}{\partial t}-d \eta_{j} \eta_{i j}(\vec{r}) \Delta-\frac{1}{2}[d(\vec{r})]_{\Gamma_{i j}}[\vec{\nabla} \ldots]_{\Gamma_{i j}} \delta\left(\vec{r}-\vec{r}_{\Gamma_{i j}}\right)- \\
-\frac{1}{2}[d(\vec{r})]_{\Gamma_{i j}}[\ldots]_{\Gamma_{i j}} \vec{\nabla} \delta\left(\vec{r}-\vec{r}_{\Gamma_{i j}}\right)-\frac{1}{2}[d(\vec{r})]_{\Gamma_{i j}}[\ldots]_{\Gamma_{i j}} \delta^{2}\left(\vec{r}-\vec{r}_{\Gamma_{i j}}\right) .
\end{gathered}
$$

In equation (19) we add and subtract the deterministic operator $L_{a}(\vec{r}, t)$, whose coefficients are quantities averaged over the volume of the body.

$$
L_{a}(\vec{r}, t)=\rho_{a} \frac{\partial}{\partial t}-d_{a} \Delta
$$

where $\rho_{a}=\sum_{j=1}^{M} v_{j} \rho_{j} ; d_{a}=\sum_{j=1}^{M} v_{j} d_{j} ; v_{j}$ is the volume fraction of spheres of the radius $R_{j}$.

For the operator $L_{a}(\vec{r}, t)$ we take into account the symmetry along the axes $x$ and $y$, then we obtain

$$
L_{a}(\vec{r}, t)=L_{a}(z, t)=\rho_{a} \frac{\partial}{\partial t}-d_{a} \frac{\partial^{2}}{\partial z^{2}}
$$

Provided the condition of continuity of the body, equation (18) takes the form

$$
L_{a}(\vec{r}, t) c(\vec{r}, t)=L_{s}^{a}(\vec{r}, t) c(\vec{r}, t),
$$


where the operator $L_{s}^{a}$ is as follows

$$
\begin{gathered}
L_{s}^{a}(\vec{r}, t)=\sum_{j=1}^{M}\left(\rho_{a}-\rho_{j}\right) \sum_{i=1}^{n_{j}} \eta_{i j}(\vec{r}) \frac{\partial}{\partial t}-\sum_{j=1}^{M}\left(d_{a}-d_{j}\right) \sum_{i=1}^{n_{j}} \eta_{i j}(\vec{r}) \Delta+ \\
\frac{1}{2} \sum_{j=1}^{M} \sum_{i=1}^{n_{j}}[d(\vec{r})]_{\Gamma_{i j}}[\vec{\nabla} \ldots]_{\Gamma_{i j}} \times \\
\times \delta\left(\vec{r}-\vec{r}_{\Gamma_{i j}}\right)+\frac{1}{2} \sum_{j=1}^{M} \sum_{i=1}^{n_{j}}[d(\vec{r})]_{\Gamma_{i j}}[\ldots]_{\Gamma_{i j}} \vec{\nabla} \delta\left(\vec{r}-\vec{r}_{\Gamma_{i j}}\right)+\frac{1}{2} \sum_{j=1}^{M} \sum_{i=1}^{n_{j}}[d(\vec{r})]_{\Gamma_{i j}}[\ldots]_{\Gamma_{i j}} \delta^{2}\left(\vec{r}-\vec{r}_{\Gamma_{i j}}\right) .
\end{gathered}
$$

Interpreting the right-hand side of equation (21) as a source, the solution of the problem (21), (2), (3), (8)-(11) can be represented as the sum of the solution of a homogeneous initialboundary value problem and the convolution of the Green's function with the source as

$$
c(\vec{r}, t)=c_{a}(\vec{r}, t)+\int_{0}^{t} \iiint_{V} G_{a}\left(\vec{r}, \vec{r}^{\prime}, t, t^{\prime}\right) L_{s}^{a}\left(\vec{r}^{\prime}, t^{\prime}\right) c\left(\vec{r}^{\prime}, t^{\prime}\right) d \vec{r}^{\prime} d t^{\prime}
$$

Here $c_{a}(\vec{r}, t)$ solution of a homogeneous equation with the operator (20) and boundary conditions (2), (3), which, taking into account the symmetry over the variables $x$ and $y$, has the form

$$
c_{a}(z, t)=c_{*}\left[1-\frac{z}{z_{0}}-\frac{2}{z_{0}} \sum_{q=1}^{\infty} \frac{1}{y_{q}} e^{-\frac{d_{a}}{\rho_{a}} y_{q}^{2} t} \sin y_{q} z\right]
$$

$G_{a}\left(\vec{r}, \vec{r}^{\prime}, t, t^{\prime}\right)$ is the deterministic Green's function of problem (21), (2), (3) with a point source, given by the following relation

$$
G_{a}\left(\vec{r}, \vec{r}^{\prime}, t, t^{\prime}\right)=\frac{\pi \theta\left(t-t^{\prime}\right)}{2 z_{0} d_{a}\left(t-t^{\prime}\right)} e^{-\frac{\rho_{a}}{4 d_{a}}\left(\frac{\left(x-x^{\prime}\right)^{2}+\left(y-y^{\prime}\right)^{2}}{t-t^{\prime}}\right)} \sum_{s=1}^{\infty} e^{-\frac{d_{a} y_{s}^{2}\left(t-t^{\prime}\right)}{\rho_{a}}} \sin \left(y_{s} z\right) \sin \left(y_{s} z^{\prime}\right),
$$

where $y_{q}=q \pi / z_{0} ; y_{s}=\left.y_{q}\right|_{q=s} ; \theta(t)$ is the Heaviside step function [15].

The solution of the integro-differential equation (22), which is equivalent to the original contact initial-boundary value problem, is sought by the iteration method in the form of the Neumann infinite integral series. As the zero approximation we take the solution of the homogeneous diffusion problem with averaged characteristics (23), then we obtain 


$$
\begin{gathered}
c(\vec{r}, t)=c_{a}(z, t)+\int_{0}^{t} \iiint_{V} G_{a}\left(\vec{r}, \vec{r}^{\prime}, t, t^{\prime}\right) L_{s}^{a}\left(\vec{r}, t^{\prime}\right) c_{a}\left(z^{\prime}, t^{\prime}\right) d \vec{r}^{\prime} d t^{\prime}+ \\
+\iiint \iint_{V} G_{a}\left(\vec{r}, \vec{r}^{\prime}, t, t^{\prime}\right) L_{s}^{a}\left(\vec{r}^{\prime}, t^{\prime}\right) \iiint \iint_{V} G_{a}\left(\vec{r}^{\prime}, \vec{r}^{\prime \prime}, t^{\prime}, t^{\prime \prime}\right) L_{s}^{a}\left(\vec{r}^{\prime \prime}, t^{\prime \prime}\right) c_{a}\left(z^{\prime \prime}, t^{\prime \prime}\right) d \vec{r}^{\prime \prime} d t^{\prime \prime} d \vec{r}^{\prime} d t^{\prime}+ \\
+\int_{0}^{t} \iiint_{V} G_{a}\left(\vec{r}, \vec{r}^{\prime}, t, t^{\prime}\right) L_{s}^{a}\left(\vec{r}^{\prime}, t^{\prime}\right) \iiint \iint_{V} G_{V}\left(\vec{r}^{\prime}, \vec{r}^{\prime \prime}, t^{\prime}, t^{\prime \prime}\right) L_{s}^{a}\left(\vec{r}^{\prime \prime}, t^{\prime \prime}\right) \times \\
\times \int_{0}^{t^{\prime \prime}} \iiint_{V} G_{a}\left(\vec{r}^{\prime \prime}, \vec{r}^{\prime \prime \prime}, t^{\prime \prime}, t^{\prime \prime \prime}\right) L_{s}^{a}\left(\vec{r}^{\prime \prime \prime}, t^{\prime \prime \prime}\right) c_{a}\left(z^{\prime \prime \prime}, t^{\prime \prime \prime}\right) d \vec{r}^{\prime \prime \prime} d t^{\prime \prime \prime} d \vec{r}^{\prime \prime} d t^{\prime \prime} d \vec{r}^{\prime} d t^{\prime}+\ldots
\end{gathered}
$$

The first term of the Neumann series (25) $c_{a}(\vec{r}, t)$ describes the field of admixture concentration in the layer with averaged parameters, the second member of this series corresponds to the perturbations that occur if spherical inclusions filled with one substance within one of the $j$ th phase, are placed alternately in such body. The third term describes the pairwise mutual influence of spherical inclusions on the concentration field, etc.

Restricting ourselves to the first two terms of the Neumann series (25)

$$
c(\vec{r}, t) \approx c_{a}(z, t)+\int_{0}^{t} \iiint_{V} G_{a}\left(\vec{r}, \vec{r}^{\prime}, t, t^{\prime}\right) L_{s}^{a}\left(\vec{r}, t^{\prime}\right) c_{a}\left(z^{\prime}, t^{\prime}\right) d \vec{r}^{\prime} d t^{\prime},
$$

we average the admixture concentration field over the ensemble of phase configurations.

The function $c_{a}\left(z^{\prime}, t^{\prime}\right)$ and its derivative are continuous functions, then, taking into account the form of the operator $L_{s}^{a}$, we obtain

$$
\begin{gathered}
c(\vec{r}, t) \approx c_{a}(z, t)+\iint_{0}^{t} \iiint_{V} G_{a}\left(\vec{r}, \vec{r}^{\prime}, t, t^{\prime}\right) \sum_{j=1}^{M} \sum_{i=1}^{n_{j}}\left[\left(\rho_{a}-\rho_{j}\right) \frac{\partial c_{a}\left(z^{\prime}, t^{\prime}\right)}{\partial t^{\prime}}-\right. \\
\left.-\left(d_{a}-d_{j}\right) \frac{\partial^{2} c_{a}\left(z^{\prime}, t^{\prime}\right)}{\partial z^{\prime 2}}\right] \eta_{i j}\left(\vec{r}^{\prime}\right) d \vec{r}^{\prime} d t^{\prime} .
\end{gathered}
$$

Assuming that spherical inclusions with different fillers are located in the body with the uniform distribution function, we average expression (26) over the ensemble of phase configurations. Also, we note that $\left\langle c_{a}(z, t)\right\rangle_{\text {conf }}=c_{a}(z, t)$, and as a random variable we consider the radius-vector of the center of the sphere $\vec{r}_{i j}$.

Then we get

$$
\eta_{i j}\left(\vec{r}^{\prime}\right)=\left\{\begin{array}{ll}
1, & \vec{r}^{\prime} \in\left(V_{i}^{(j)}\right) \\
0, & \vec{r}^{\prime} \notin\left(V_{i}^{(j)}\right)
\end{array}=\left\{\begin{array}{ll}
1, & \left|\vec{r}^{\prime}-\vec{r}_{i j}\right| \in\left[0 ; R_{j}\right] \\
0, & \left|\vec{r}^{\prime}-\vec{r}_{i j}\right| \notin\left[0 ; R_{j}\right]
\end{array}=\eta_{i j}\left(\left|\vec{r}^{\prime}-\vec{r}_{i j}\right|\right) .\right.\right.
$$

Here $j=\overline{1, M} ; i=\overline{1, n_{j}}$. 
Given that the density of the uniform distribution function is $1 / V$, and only the function $\eta_{i j}$ depends on the radius-vectors of the centers of the spheres, the second term in (27) can be represented as:

$$
\begin{aligned}
\langle I\rangle_{\text {conf }} & =\int_{0}^{t} \iiint_{V} G_{a}\left(\vec{r}, \vec{r}^{\prime}, t, t^{\prime}\right) \sum_{j=1}^{M} \sum_{i=1}^{n_{j}}\left[\left(\rho_{a}-\rho_{j}\right) \frac{\partial c_{a}\left(z^{\prime}, t^{\prime}\right)}{\partial t^{\prime}}-\right. \\
- & \left.\left(d_{a}-d_{j}\right) \frac{\partial^{2} c_{a}\left(z^{\prime}, t^{\prime}\right)}{\partial z^{\prime 2}}\right] \iiint_{V} \eta_{i j}\left(\vec{r}^{\prime}\right) d \vec{r}_{i j} d \vec{r}^{\prime} d t^{\prime}
\end{aligned}
$$

By passing to the spherical coordinate system, as well as taking into account the relation $\frac{4}{3} \frac{n_{j} \pi}{V}=\frac{4 n_{j} \pi R_{j}^{3}}{3 V R_{j}^{3}}=\frac{v_{j}}{R_{j}^{3}}$, for expression (28) we obtain

$$
\begin{aligned}
\langle I\rangle_{\text {conf }}= & \sum_{j=1}^{M} v_{j} \int_{0}^{t} \int_{-\infty}^{\infty} \int_{-\infty}^{\infty}\left[\int_{0}^{2 R_{j}}\left(\frac{z^{\prime}}{R_{j}}-1\right)^{3} G_{a}\left[\left(\rho_{a}-\rho_{j}\right) \frac{\partial c_{a}}{\partial t^{\prime}}-\left(d_{a}-d_{j}\right) \frac{\partial^{2} c_{a}}{\partial z^{\prime 2}}\right] d z^{\prime}+\right. \\
& \left.+\int_{2 R_{j}}^{z_{0}} G_{a}\left[\left(\rho_{a}-\rho_{j}\right) \frac{\partial c_{a}}{\partial t^{\prime}}-\left(d_{a}-d_{j}\right) \frac{\partial^{2} c_{a}}{\partial z^{\prime 2}}\right] d z^{\prime}\right] d y^{\prime} d x^{\prime} d t^{\prime}
\end{aligned}
$$

Thus, the general formula (29) for determining the averaged over the ensemble of phase configurations concentration field of the migrating substance in a layer with randomly located spheres of $N$ different physical characteristics (phases) with $M$ different characteristic radii under the condition of the uniform distribution of inclusions is obtained

$$
\begin{gathered}
\langle c(\vec{r}, t)\rangle_{\text {conf }}=c_{a}(z, t)+\sum_{j=1}^{M} v_{j} \int_{0}^{t} \int_{-\infty}^{\infty} \int_{-\infty}^{\infty}\left[\int _ { 0 } ^ { 2 R _ { j } } ( \frac { z ^ { \prime } } { R _ { j } } - 1 ) ^ { 3 } G _ { a } \left[\left(\rho_{a}-\rho_{j}\right) \frac{\partial c_{a}}{\partial t^{\prime}}-\right.\right. \\
\left.\left.-\left(d_{a}-d_{j}\right) \frac{\partial^{2} c_{a}}{\partial z^{\prime 2}}\right] d z^{\prime}+\int_{2 R_{j}}^{z_{0}} G_{a}\left[\left(\rho_{a}-\rho_{j}\right) \frac{\partial c_{a}}{\partial t^{\prime}}-\left(d_{a}-d_{j}\right) \frac{\partial^{2} c_{a}}{\partial z^{\prime 2}}\right] d z^{\prime}\right] d y^{\prime} d x^{\prime} d t^{\prime} .
\end{gathered}
$$

Note that formulae (28) and (30) are valid for arbitrary initial and boundary conditions.

Substituting the expressions for the Green's function $G_{a}\left(\vec{r}, \vec{r}^{\prime}, t, t^{\prime}\right)$ (24) and the concentration in the homogeneous layer with averaged characteristics $c_{a}(\vec{r}, t)(23)$ into formula (30), we obtain the calculation formula for the averaged over the ensemble of phase configurations particle concentration in a multiphase randomly nonhomogeneous body with the uniform distribution of spherical inclusions and commensurable volume fractions of phases under boundary conditions of the first kind

$$
\langle c(\vec{r}, t)\rangle_{\text {conf }} \approx c_{a}(z, t)+\sum_{j=1}^{M} \frac{2 c_{*} v_{j} \pi^{2} K_{d \rho}^{j}}{\rho_{a} z_{0}^{2}} \sum_{s=1}^{\infty} \sin \left(y_{s} z\right)\left(A_{s}^{j} e^{-d_{a} y_{s}^{2} t / \rho_{a}}+\right.
$$




$$
\left.+\sum_{\substack{q=1 \\ q \neq s}}^{\infty} A_{s q}^{j}\left[e^{-d_{a} y_{s}^{2} t / \rho_{a}}-e^{-d_{a} y_{q}^{2} t / \rho_{a}}\right]\right)
$$

where

$$
\begin{gathered}
K_{d \rho}^{j}=d_{j}-d_{a} \frac{\rho_{j}}{\rho_{a}} ; y_{s q}^{ \pm}=y_{s} \pm y_{q} ; A_{s}^{j}=y_{s}\left\{z_{0}-2 R_{j}-B_{c}^{j}\left(2 y_{s}\right)+\frac{\sin \left(4 y_{s} R_{j}\right)}{2 y_{s}}\right\} ; \\
A_{s q}^{j}=\frac{y_{q} \rho_{a}}{d_{a}\left(y_{q}^{2}-y_{s}^{2}\right)}\left\{B_{c}^{j}\left(y_{s q}^{-}\right)-B_{c}^{j}\left(y_{s q}^{+}\right)-\frac{\sin \left(2 R_{j} y_{s q}^{-}\right)}{y_{s q}^{-}}+\frac{\sin \left(2 R_{j} y_{s q}^{+}\right)}{y_{s q}^{+}}\right\} ; \\
B_{c}^{j}(\omega)=\frac{1}{R_{j}^{3}}\left[\frac{3}{\omega^{2}}\left(R_{j}^{2}-\frac{2}{\omega^{2}}\right)\left(\cos \left(2 R_{j} \omega\right)-1\right)+\frac{R_{j}}{\omega}\left(R_{j}^{2}-\frac{6}{\omega^{2}}\right) \sin \left(2 R_{j} \omega\right)\right]
\end{gathered}
$$

is the function of the independent variable $\omega$.

Numerical analysis of diffusion in the randomly nonhomogeneous body with spherical inclusions of different materials. We carry out a quantitative study of the mass transfer of the admixture in the body with spherical inclusions and commensurable volume fractions of phases, assuming that the materials of the phases of inclusions have a fundamentally different physical nature (for example, solid and gas mixture). Calculations are performed in the dimensionless variable $\varsigma=z / z_{0}$ and $\tau=d_{0} t / z_{0}^{2}$ [16] according to the calculation formula (31), in which the accuracy of calculating the series by $s$ is $10^{-7}$, and by $q$ equals $10^{-9}$. We assume that the skeleton of the body has a dimensionless diffusion coefficient $d_{0}=0.001$ and density $\rho_{0}=1.05$; inclusions that correspond to the solid phase have the characteristics $d_{1}=0.1$ and $\rho_{1}=3$; for inclusions with the gaseous filler coefficients $d_{2}=0.8$ and $\rho_{2}=0.15$ are taken, i.e. the body has a three-phase structure $(N=2)$. This order of the ratios of the diffusion coefficients and density of the skeleton material and inclusions corresponds to the materials existing in nature. However, in order not to reduce the generality of studies of the basic regularities of the distribution of the admixture substance concentration, we consider the structure as a kind of abstract material, and the exact characteristics of the medium are set depending on the specific application problem.

Suppose there are 3 types of spheres with different radii for modeling a skeleton packing, 3 types of spheres of different radii for describing inclusions of the first phase and 2 types of spheres for modeling inclusions of the second phase. In the notation of the problem, we have $m_{0}=3, m_{1}=3, m_{2}=2$, hence $M=8$. Characteristic radii and volume fractions of each phase is written in the form of vectors $\bar{R}_{0}=\left(R_{1}, R_{2}, R_{3}\right), \bar{R}_{1}=\left(R_{4}, R_{5}, R_{6}\right), \bar{R}_{2}=\left(R_{7}, R_{8}\right)$ and $\bar{v}_{0}=\left(v_{1}, v_{2}, v_{3}\right), \quad \bar{v}_{1}=\left(v_{4}, v_{5}, v_{6}\right), \quad \bar{v}_{2}=\left(v_{7}, v_{8}\right)$. Basic characteristics for calculations are $\bar{R}_{0}=\left(10^{-2} ; 10^{-3} ; 5 \cdot 10^{-3}\right), \bar{R}_{1}=\left(10^{-3} ; 5 \cdot 10^{-3} ; 10^{-4}\right), \bar{R}_{2}=\left(10^{-2} ; 10^{-3}\right)$, and the values of the volume fractions are $\bar{v}_{0}=(0.15 ; 0.1 ; 0.05), \bar{v}_{1}=(0.15 ; 0.15 ; 0.1), \bar{v}_{2}=(0.2 ; 0.1)$. Thus, inclusions of the solid phase occupy $40 \%$ of the body volume, inclusions with gas filler take up $30 \%$ of the body volume, $30 \%$ is the body skeleton. 
Figure 2 shows distributions of the admixture concentration in the body with spherical inclusions at dimensionless times $\tau=0.3 ; 0.4 ; 0.5 ; 0.6 ; 0.8$ (curves $1-5$ ). Dashed lines (curves a) are plotted for the homogeneous body (without spherical inclusions) with characteristics averaged over the volume of the body, solid lines (curves b) correspond to functions of admixture concentration averaged over the ensemble of phase configurations. Here the characteristics averaged over the body volume are $d_{a}=0.2803, \rho_{a}=1.53$.

Figure 3 illustrates the behavior of the concentration of admixture particles averaged over the ensemble of phase configurations and of the concentration in the homogeneous body with characteristics averaged over the body volume for different values of the volume fraction of spherical inclusions at a constant value of the volume fraction of the base phase $\left(v_{0}=0.3\right)$. Curves $1-4$ are plotted for the values of the total volume fraction of solid inclusions $0.1 ; 0.35$; $0.4 ; 0.5$ (the volume fraction of the gaseous phase is $0.6 ; 0.35 ; 0.3 ; 0.2$ ). In this case, the distributions of particles for each characteristic radius are as follows: $\bar{v}_{1}=(0.04 ; 0.04 ; 0.02)$, $\bar{v}_{2}=(0.4 ; 0.2) \quad$ for curves $1, \quad \bar{v}_{1}=(0.15 ; 0.15 ; 0.05), \quad \bar{v}_{2}=(0.2 ; 0.15)$ for curves 2 , $\bar{v}_{1}=(0.15 ; 0.15 ; 0.1), \bar{v}_{2}=(0.2 ; 0.1)$ curves $3, \bar{v}_{1}=(0.2 ; 0.2 ; 0.1), \bar{v}_{2}=(0.13 ; 0.07)$ curves 4 , and the characteristics averaged over the volume of the body are $d_{a}=0.2503 ; 0.3153 ; 0.2803$; 0.2103 and $\rho_{a}=0.63 ; 1.3825 ; 1.53 ; 1.825$, respectively (curves 1 a -4 a, Fig. 3 ). Hereinafter, the calculations are performed at the dimensionless moment of time $\tau=0.5$.

Note that for small times of the diffusion process, the averaged concentrations of the migrating substance in the body with spherical inclusions are convex upward functions (curves b, Fig. 2), and smaller values of dimensionless time represent greater global maximum of the function $\langle c(\zeta, \tau)\rangle / c_{*}$. The concentration function of the admixture substance in a body without spherical inclusions with characteristics averaged over the volume of the body is a monotonically decreasing function, convex downward, the value of which increases with increasing dimensionless time $\tau$ (curves a, Fig. 2).

An increase in the volume fraction of spherical inclusions of the solid phase with a simultaneous decrease in the volume fraction of spherical inclusions with gaseous filler causes a decrease in the concentration of the migrating substance in a homogeneous body (curves a, Fig. 3). But the increase in the number of spherical inclusions of the solid phase with a simultaneous decrease in the number of inclusions of the second phase increases the value of the averaged concentration in the body first (curve 2 b, Fig. 3), and then the value of the averaged concentration of the migrating substance decreases (curves $3 \mathrm{~b}$ and $4 \mathrm{~b}$, Fig. 3 ).

Figure 4 illustrates distributions of the function $\langle c(\varsigma, \tau)\rangle / c_{*}$ for different numbers of characteristic radii of spheres filled with gaseous substance under condition of the constant volume fraction of the second phase $\left(v_{2}=0.3\right)$. Curve 1 (dashed line) is plotted for the basic values of parameters, that is, for two characteristic radii of the spherical inclusions of the second phase $\bar{R}_{2}=\left(10^{-2} ; 10^{-3}\right)$, which correspond to the volume fractions $\bar{v}_{2}=(0.2 ; 0.1)$; Curves 2 and 3 correspond to the averaged concentration in the body, in which three characteristic radii of inclusions of the second phase $\bar{R}_{2}=\left(10^{-2} ; 10^{-3} ; 5 \cdot 10^{-3}\right)$ and $\bar{R}_{2}=\left(10^{-2} ; 10^{-3} ; 5 \cdot 10^{-2}\right)$ are distinguished for the same distribution of volume fractions $\bar{v}_{2}=(0.17 ; 0.08 ; 0.05)$. Curves 4 and 5 in Fig. 4 are plotted for the same set of characteristic radii of inclusions filled with gaseous substance $\bar{R}_{2}=\left(10^{-2} ; 10^{-3} ; 3 \cdot 10^{-2}\right)$, but for different distributions of volume fractions which relate to the inclusion of each radii, $\bar{v}_{2}=(0.1 ; 0.05 ; 0.15)$ and $\bar{v}_{2}=(0.12 ; 0.09 ; 0.19)$. Curves 6 and 7 correspond to the averaged 
admixture concentration in the body, in which four different characteristic radii of inclusions of the second phase $\bar{R}_{2}=\left(10^{-2} ; 10^{-3} ; 5 \cdot 10^{-2} ; 3 \cdot 10^{-2}\right)$ and $\bar{R}_{2}=\left(10^{-2} ; 10^{-3} ; 5 \cdot 10^{-3} ; 5 \cdot 10^{-2}\right)$ are distinguished, herewith volume fractions equals $\bar{v}_{2}=(0.1 ; 0.05 ; 0.05 ; 0.1)$. Curve 8 (Fig. 4) is plotted for a structure in which spherical inclusions with a gaseous filler of five different radii $\bar{R}_{2}=\left(10^{-2} ; 10^{-3} ; 3 \cdot 10^{-3} ; 5 \cdot 10^{-3} ; 5 \cdot 10^{-2}\right)$ are distinguished with corresponding volume fractions $\bar{v}_{2}=(0.1 ; 0.02 ; 0.01 ; 0.02 ; 0.15)$.

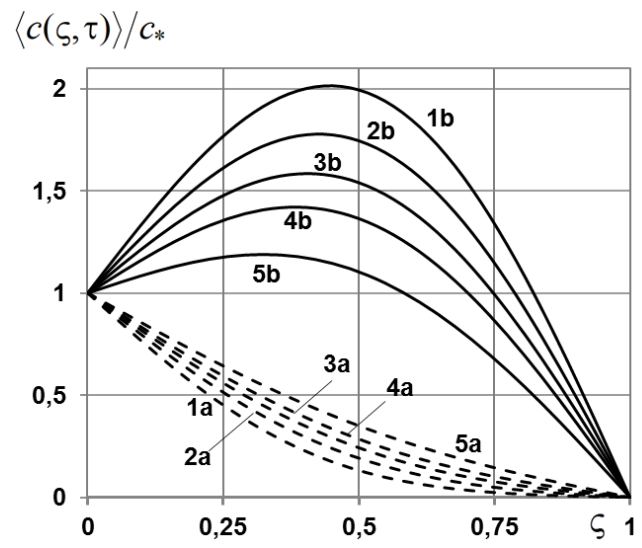

Figure 2. Distributions of admixture concentration at different moments of dimensionless time

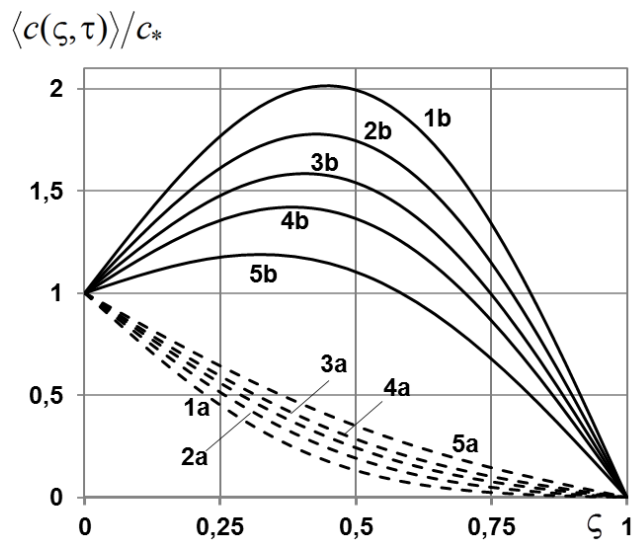

Figure 3. Distributions of admixture concentration for various volume fractions of inclusions

For given basic values of input parameters of the problem, a change in the number of characteristic radii of spherical inclusions of a solid phase causes negligible changes in the averaged concentration of admixture substance throughout the body. Namely, 8th or 9th significant digits change, which are beyond the accuracy of calculating the sum of the series according to the calculation formula (31). On the other hand, a change in the number of characteristic radii of spheres filled with a gaseous substance with a constant volume fraction of the second phase causes both quantitative and qualitative changes in the behavior of the average concentration function $\langle c(\varsigma, \tau)\rangle / c_{*}$ (Fig. 4). In particular, the separation of the third characteristic radius for inclusions of the second phase can both decrease (curves 2 and 3, Fig. 4) and increase almost twice (curve 4, Fig. 4) the value of the averaged concentration. In this case, for the characteristic radii of spheres with gaseous filler $5 \cdot 10^{-3}$ and $5 \cdot 10^{-2}$ with the same distribution of volume fractions between spheres of different phases and radii the values of the average concentration differ by no more than $2 \%$ (curves 2 and 3, Fig. 4). A similar situation is observed in the case of the separation of four different characteristic radii, which have the same distribution of volume fractions of the body (curves 6 and 7, Fig. 4), the difference between the values of function $\langle c(\varsigma, \tau)\rangle / c_{*}$ reaches no more than $1.5 \%$. However, for the same set of characteristic radii of inclusions filled with a gaseous substance, but different distributions of volume fractions correspond to the inclusion of each radius, the difference in the values of the averaged admixture concentration in the body can reach up to $61 \%$ (curves 4 and 5, Fig. 4). Consequently, values of the function of the averaged concentration of the migrating substance in the body are 
most sensitive to the values of the volume fractions attributable to spherical inclusions with gaseous substance, while the values of the characteristic radii have a less effect.

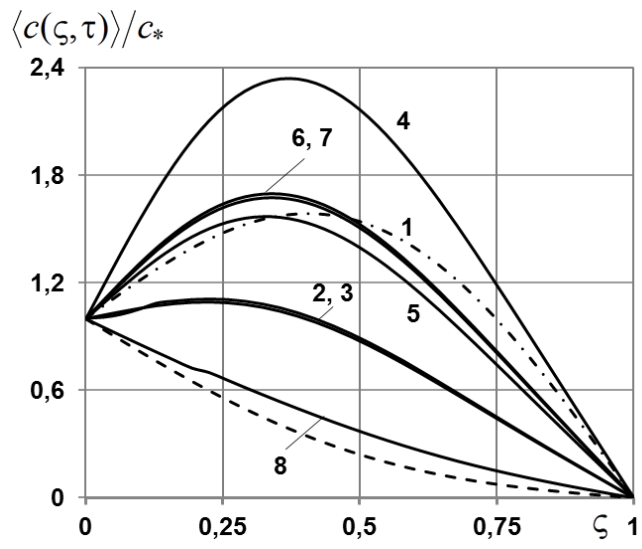

Figure 4. Distributions of admixture concentration for different number of characteristic radii of the second phase

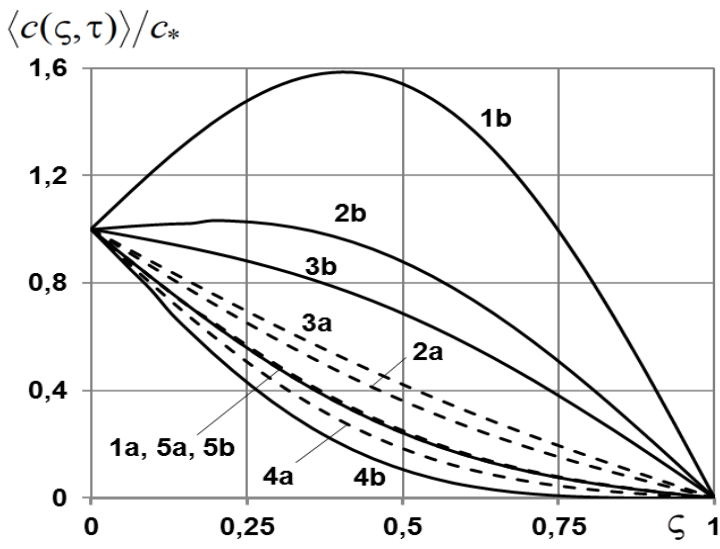

Figure 5. Distributions of admixture concentration for different number of phases

An increase in the number of phases due to solid or gaseous inclusions for the given parameters of the problem decreases the value of the averaged concentration (Fig. 5). In this case, the function $\langle c(\zeta, \tau)\rangle / c_{*}$ in a four- and five-phased body with two and three gaseous phases, respectively, is a convex upward function, the value of which is greater than concentration in a homogeneous body with characteristics averaged over the body volume ( $2 \mathrm{~b}$ and 3 b, Fig. 5). For structures with two or three phases of solid inclusions, the function of the averaged concentration is a monotonically decreasing function, the value of which is less than the admixture concentration in a homogeneous body ( $4 \mathrm{~b}$ and 5 b, Fig. 5).

Investigation of the influence of dense skeleton packing by spheres of different radii on the averaged concentration of migrating substance. Let us study the dependence of the averaged admixture concentration on different variants of modeling the skeleton of the structure by dense packing of spheres of various radii. Table 1 and Table 2 show the calculated data of the concentration of migrating substance in the body with characteristics averaged over the body volume $c_{a}(\varsigma, \tau) / c_{*}$ and the averaged concentration in the body $c_{1}(\varsigma, \tau) / c_{*}$ for the basic values of the input parameters of the problem from the previous subsection, namely, when the body skeleton is modeled by spheres of three characteristic radii $\bar{R}_{0}=\left(10^{-2} ; 10^{-3} ; 5 \cdot 10^{-3}\right)$ with volume fractions $\bar{v}_{0}=(0.15 ; 0.1 ; 0.05)$. Table 1 shows a comparison of the distribution of the averaged concentration $c_{1}(\varsigma, \tau) / c_{*}$ with the values of the averaged concentration in the structures, the skeleton of which is modeled by spheres of the same characteristic radius. In particular, $c_{2}(\zeta, \tau) / c_{*}$ is calculated for the characteristic radius of the skeleton $R_{0}=0.00342$, which is the average value of the characteristic radii of spherical inclusions of the solid $\bar{R}_{1}$ and gaseous $\bar{R}_{2}$ phases; $c_{3}(\varsigma, \tau) / c_{*}$ corresponds to the values of the averaged concentration in the structure, the skeleton of which is modeled by spheres of radius $R_{0}=0.0001$ (radius of the smallest inclusion); $c_{4}(\varsigma, \tau) / c_{*}$ is calculated for the characteristic radius $R_{0}=0.00001$ (radius of an order of magnitude less than the radius of the smallest spherical inclusion). Note that the calculation is performed at the moment of time $\tau=0.5$ and for the volume fraction of the skeleton $v_{0}=0.3$. 
Table 1

Concentration the admixture for one characteristic radius of spheres modeling the skeleton of the body

\begin{tabular}{|c|c|c|c|c|c|}
\hline$\varsigma$ & $c_{a}(\varsigma, \tau) / c_{*}$ & $c_{1}(\zeta, \tau) / c_{*}$ & $c_{2}(\zeta, \tau) / c_{*}$ & $c_{3}(\zeta, \tau) / c_{*}$ & $c_{4}(\zeta, \tau) / c_{*}$ \\
\hline $\mathbf{0 . 0 0 0}$ & 1.0000000000 & 1.0000000000 & 1.0000000000 & 1.0000000000 & 1.0000000000 \\
\hline $\mathbf{0 . 1 2 5}$ & 0.7680683640 & 1.2525973378 & 1.2525973375 & 1.2525973375 & 1.2525973375 \\
\hline $\mathbf{0 . 2 5 0}$ & 0.5553011051 & 1.4505938655 & 1.4505938648 & 1.4505938648 & 1.4505938648 \\
\hline $\mathbf{0 . 3 7 5}$ & 0.3762075985 & 1.5459639522 & 1.5459639514 & 1.5459639514 & 1.5459639514 \\
\hline $\mathbf{0 . 5 0 0}$ & 0.2376997718 & 1.5038349082 & 1.5038349073 & 1.5038349073 & 1.5038349073 \\
\hline $\mathbf{0 . 6 2 5}$ & 0.1391803560 & 1.3089366674 & 1.3089366667 & 1.3089366667 & 1.3089366667 \\
\hline $\mathbf{0 . 7 5 0}$ & 0.0736476687 & 0.9689403508 & 0.9689403503 & 0.9689403503 & 0.9689403503 \\
\hline $\mathbf{0 . 8 7 5}$ & 0.0310415720 & 0.5155704435 & 0.5155704433 & 0.5155704433 & 0.5155704433 \\
\hline $\mathbf{1 . 0 0 0}$ & 0.0000000000 & 0.0000000000 & 0.0000000000 & 0.0000000000 & 0.0000000000 \\
\hline
\end{tabular}

In Table 2, values $c_{2}(\varsigma, \tau) / c_{*}$ and $c_{3}(\zeta, \tau) / c_{*}$ are calculated for the case of two characteristic radii of the skeleton balls, namely $\bar{R}_{0}=\left(10^{-3} ; 10^{-4}\right)$, but different ratios of volume fractions for these two radii $\bar{v}_{0}=(0.15 ; 0.15)$ and $\bar{v}_{0}=(0.05 ; 0.25)$, respectively; values $c_{4}(\zeta, \tau) / c_{*}$ correspond to the averaged concentration of the migrating substance in the body, the skeleton of which is modeled by three characteristic radii $\bar{R}_{0}=\left(10^{-3} ; 10^{-4} ; 10^{-5}\right)$ with volume fractions $\bar{v}_{0}=(0.05 ; 0.1 ; 0.15)$.

Table 2

Concentration of the admixture for several characteristic radii of spheres modeling the skeleton of the body

\begin{tabular}{|l|l|l|l|l|l|}
\hline$\varsigma$ & $c_{a}(\varsigma, \tau) / c_{*}$ & $c_{1}(\varsigma, \tau) / c_{*}$ & $c_{2}(\varsigma, \tau) / c_{*}$ & $c_{3}(\varsigma, \tau) / c_{*}$ & $c_{4}(\varsigma, \tau) / c_{*}$ \\
\hline $\mathbf{0 . 0 0 0}$ & 1.0000000000 & 1.0000000000 & 1.0000000000 & 1.0000000000 & 1.0000000000 \\
\hline $\mathbf{0 . 1 2 5}$ & 0.7680683640 & 1.2525973378 & 1.2525973375 & 1.2525973386 & 1.2525973378 \\
\hline $\mathbf{0 . 2 5 0}$ & 0.5553011051 & 1.4505938655 & 1.4505938648 & 1.4505938669 & 1.4505938655 \\
\hline $\mathbf{0 . 3 7 5}$ & 0.3762075985 & 1.5459639522 & 1.5459639514 & 1.5459639539 & 1.5459639522 \\
\hline $\mathbf{0 . 5 0 0}$ & 0.2376997718 & 1.5038349082 & 1.5038349073 & 1.5038349099 & 1.5038349082 \\
\hline $\mathbf{0 . 6 2 5}$ & 0.1391803560 & 1.3089366674 & 1.3089366667 & 1.3089366689 & 1.3089366674 \\
\hline $\mathbf{0 . 7 5 0}$ & 0.0736476687 & 0.9689403508 & 0.9689403503 & 0.9689403518 & 0.9689403508 \\
\hline $\mathbf{0 . 8 7 5}$ & 0.0310415720 & 0.5155704435 & 0.5155704433 & 0.5155704441 & 0.5155704435 \\
\hline $\mathbf{1 . 0 0 0}$ & 0.0000000000 & 0.0000000000 & 0.0000000000 & 0.0000000000 & 0.0000000000 \\
\hline
\end{tabular}

Note that for the given input parameters of the problem, in particular, within a given accuracy, the differences between the averaged concentrations of admixture particles in the body whose skeleton is modeled by a dense packing of spheres of one, two and three radii are reached at maximum in 10th significant digit, which is a negligible value (Tables 1 and 2). At the same time, in the case of modeling the body skeleton with spheres of the same radius, values of the averaged concentration of migrating particles are coincide for the characteristic radius which is the average value of inclusions radii, for radius corresponds to the smallest spherical 
inclusion and for the radius an order of magnitude smaller than this value (Table 1). Therefore, to simplify the calculations in modeling the skeleton of a body with a dense packing of spheres, we can recommend using a model with one characteristic radius of the skeleton, which is, for example, the characteristic radius of the smallest spherical inclusion.

Let us carry out a comparative analysis of the concentration of a migrating substance in the body for two models of admixture diffusion, namely, for a model in which there is a phase with a prevailing volume fraction [13] and a model with a proportional volume fractions considered in this work. The following values of the input parameters of the problem are accepted: $\tau=0.5$; diffusion coefficients are equal to $d_{0}=0.1 ; d_{1}=0.5 ; d_{2}=1.5$; the densities of the materials are $\rho_{0}=1.15 ; \rho_{1}=1.3 ; \rho_{2}=1.05$; radii of the spherical inclusions are as follows $\bar{R}_{1}=\left(10^{-2} ; 5 \cdot 10^{-3} ; 10^{-3}\right), \bar{R}_{2}=\left(10^{-2} ; 10^{-3}\right)$ and values of the corresponding volume fractions are $\bar{v}_{1}=(0.1 ; 0.05 ; 0.05), \bar{v}_{2}=(0.15 ; 0.05)$.

In Table 3 values $c(\varsigma, \tau) / c_{*}$ correspond to the model of diffusion in a body with a «solid base», values $c_{j}(\varsigma, \tau) / c_{*}(j=\overline{1,4})$ are calculated by formula (31) and correspond to the structure in which the skeleton is modeled by dense packing of spheres. In particular, $c_{1}(\varsigma, \tau) / c_{*}$ is calculated for $\bar{R}_{0}=\left(10^{-3}\right), \bar{v}_{0}=(0.6) ; c_{2}(\varsigma, \tau) / c_{*}$ is calculated for the average radius of all spherical inclusions $\bar{R}_{0}=\left(5,4 \cdot 10^{-3}\right), \bar{v}_{0}=(0.6) ; c_{3}(\varsigma, \tau) / c_{*}$ is calculated for two characteristic skeleton radii $\bar{R}_{0}=\left(10^{-3} ; 10^{-4}\right), \bar{v}_{0}=(0.2 ; 0.4) ; c_{4}(\varsigma, \tau) / c_{*}$ is calculated for three characteristic radii of the skeleton of the body $\bar{R}_{0}=\left(10^{-3} ; 10^{-4} ; 5 \cdot 10^{-4}\right)$, $\bar{v}_{0}=(0.2 ; 0.25 ; 0.15)$.

\section{Table 3}

Comparative analysis of the admixture concentration for the solid base of the body and the skeleton modeled by spheres

\begin{tabular}{|c|c|c|c|c|c|}
\hline$\varsigma$ & $c(\varsigma, \tau) / c_{*}$ & $c_{1}(\varsigma, \tau) / c_{*}$ & $c_{2}(\zeta, \tau) / c_{*}$ & $c_{3}(\varsigma, \tau) / c_{*}$ & $c_{4}(\varsigma, \tau) / c_{*}$ \\
\hline $\mathbf{0 . 0 0 0}$ & 1.0000000000 & 1.0000000000 & 1.0000000000 & 1.0000000000 & 1.0000000000 \\
\hline $\mathbf{0 . 1 2 5}$ & 1.4862779512 & 0.9971033015 & 0.9971033015 & 0.9971033003 & 0.9971033003 \\
\hline $\mathbf{0 . 2 5 0}$ & 1.8794913482 & 0.9756563795 & 0.9756563795 & 0.9756563774 & 0.9756563774 \\
\hline $\mathbf{0 . 3 7 5}$ & 2.1007476893 & 0.9199103250 & 0.9199103250 & 0.9199103223 & 0.9199103223 \\
\hline $\mathbf{0 . 5 0 0}$ & 2.0973336259 & 0.8193057314 & 0.8193057314 & 0.8193057284 & 0.8193057284 \\
\hline $\mathbf{0 . 6 2 5}$ & 1.8507490100 & 0.6700897356 & 0.6700897356 & 0.6700897328 & 0.6700897328 \\
\hline $\mathbf{0 . 7 5 0}$ & 1.3794931927 & 0.4759100997 & 0.4759100997 & 0.4759100976 & 0.4759100976 \\
\hline $\mathbf{0 . 8 7 5}$ & 0.7362778234 & 0.2472826969 & 0.2472826969 & 0.2472826957 & 0.2472826957 \\
\hline $\mathbf{1 . 0 0 0}$ & 0.0000000000 & 0.0000000000 & 0.0000000000 & 0.0000000000 & 0.0000000000 \\
\hline
\end{tabular}

Note that values of the averaged concentration of the migrating substance for two models of admixture diffusion in a body with spherical inclusions differ by almost three times, while values of the concentration in a body whose skeleton is modeled by a dense packing of spheres of different radii are less one. In addition, as in the case of calculations for the structure with solid and gaseous inclusions, the use of different variants of dense packing 
of the body skeleton affects no more than the 9th significant digit of the value of averaged admixture (Table 3 ).

Conclusions. In the paper the process of migration of admixture substance in a multiphase body with spherical inclusions in the case of absence a prevailing volume fraction of any phase is investigated. The mathematical model for describing the process of mass transfer is built according to the theory of binary systems, and the contact initial-boundary value problem is formulated in a three-dimensional formulation taking into account the jumps of the unknown function and its derivative at the phase boundaries. The body skeleton is modeled by a dense packing of spheres of different characteristic radii for the application of a unified approach to studying multiphase randomly nonhomogeneous bodies. The differential equation of mass transfer for the whole body is constructed, as well as an integro-differential equation equivalent to the obtained boundary value problem, the solution of which is found in the form of the Neumann series. Restricting ourselves to the first two terms of this series, the procedure of averaging over the ensemble of phase configurations with the uniform distribution function of spherical inclusions in the body is carried out. The calculation formula for the averaged field of particle concentration in the multiphase body with spherical inclusions of different materials and different characteristic radii is obtained. The analysis of the dependence of the migrating substance concentration in the body with spherical inclusions with commensurable volume fractions of phases on the parameters of the media is carried out. In particular, the case of the medium in which the materials of the phases of the inclusions have a fundamentally different physical nature, such as the solid and gaseous mixture, is considered. It is shown that a change in the number of characteristic radii, which simulate the spherical inclusions of the solid phase, causes negligible changes in the averaged concentration of admixture throughout the body. Whereas a change in the number of characteristic radii of spheres filled with a gaseous substance, with a constant volume fraction of the second phase, causes both quantitative and qualitative changes in the behavior of the averaged concentration function. The influence of the dense packing density of the skeleton by spheres with different radii is investigated. The differences between the numerical results obtained for different variants of dense packing of the body skeleton turned out to be negligible; therefore, it is recommended for this type of problems to simplify calculations use a model with one characteristic skeleton radius, for example, equal to the characteristic radius of the smallest spherical inclusion. On the other hand, a comparison of the models of mass transfer in a medium with a solid skeleton and in the skeleton simulated by dense packing of spheres showed significant differences in the values of the concentration of the migrating substance. This means that during the study of filtration and mass transfer processes in soils, which are usually considered as a dense packing of microgranules (fictitious soil model), the adequacy of modeling the skeleton of the media by a solid body is questionable, and therefore requires further research.

\section{References}

1. Coutelieris A. F., Delgado J. M. P. Q. Transport Processes in Porous Media, Berlin, Springer, 2012, 235 p. DOI: https://doi.org/10.1007/978-3-642-27910-2

2. Kovbashyn V., Bochar I. The study of technologies to improve physical-mechanical and chemical properties of reaction sintered ceramic materials on the basis of silicon carbide. Scientific Journal of TNTU. Vol. 86. No. 2. 2017. P. 14-20.

3. Van Kampen N. G. Stochastic Processes in Chemistry and Physics, Norwell, Elsevier, 1992, 480 p.

4. Vamoş C., Suciua N., Vereecken H. Generalized random walk algorithm for the numerical modeling of complex diffusion processes, Journal of Computational Physics, Vol. 186 (2). 2003. P. 527-544. DOI: https://doi.org/10.1016/S0021-9991(03)00073-1

5. LaBolle E. M., Quastel J., Fogg E. G., Gravner J. Diffusion processes in composite porous media and their numerical integration by random walks: Generalized stochastic differential equations with discontinuous coefficients. Water Resources Research. Vol. 36 (3). 2000. P. 651-662. DOI: https://doi.org/10.1029/1999WR900224 
6. Yong Y., Lou X., Li S., Yang C., Yin X. Direct simulation of the influence of the pore structure on the diffusion process in porous media, Computers \& Mathematics with Applications. Vol. 67 (2). 2014. P. 412-423. DOI: https://doi.org/10.1016/j.camwa.2013.08.032

7. Hlushkou V., Khirevich S., Apanasovich V.V., Tallarek U. Pore-scale dispersion in electrokinetic flow through a random sphere packing, Analytical Chemistry. 79. 2007. P. 113-121. DOI: https://doi.org/10.1021/ac061168r

8. Chaplia Y., Chernukha O. Three-dimensional diffusion in a multiphase body with randomly disposed inclusions of a spherical form, International Journal of Heat and Mass Transfer, Vol. 46. 2003. P. 33233328. DOI: https://doi.org/10.1016/S0017-9310(03)00123-6

9. Chaplia Ye., Chernukha O. Fizyko-matematychne modeliuvannia dyfuziinykh protsesiv u vypadkovykh i rehuliarnykh strukturakh. Kyiv: Naukova dumka, 2009. 302 p. [In Ukrainian].

10. Chernukha O., Bilushchak Yu., Chuchvara A. Modeliuvannia dyfuziinykh protsesiv u stokhastychno neodnoridnykh strukturakh. Lviv: Rastr-7, 2016. 262 p. [In Ukrainian].

11. Gyarmati J. Non-equilibrium Thermodynamics. Field Theory and Variational Principles. Berlin, Springer, 1970, 184 p. DOI: https://doi.org/10.1007/978-3-642-51067-0

12. Münster A. Classical Thermodynamics. Wiley Interscience, 1970, 387 p.

13. Chernukha O., Chuchvara A. Modeliuvannia dyfuzii domishkovoi rechovyny u porystomu tili z vypadkovymy sferychnymy poramy pry sumirnykh obiemnykh chastkakh faz. Mat. metody ta fiz.-mekh. polia. 62. № 1. 2019. P. 150-161. [In Ukrainian].

14. Rytov S. M., Kravtsov Yu. A., Tatarskyi V. Y. Vvedenie v statisticheskuiu radiofiziku II. Sluchainye polia. Moskva: Nauka, 1978. 464 p. [In Russian].

15. Spravochnik po spetsyalnym funktsyiam / pod red. M. Abramovitsa i Y. Styhan. Moskva: Mir, 1979, 830 p. [In Russian].

16. Lykov A. V. Teoriia teploprovodnosti. Moskva: Vysshaia shkola, 1978. 480 p. [In Russian].

\section{Список використаної літератури}

1. Coutelieris A. F., Delgado J. M. P. Q. Transport Processes in Porous Media. Berlin: Springer, 2012. 235 p. DOI: https://doi.org/10.1007/978-3-642-27910-2

2. Kovbashyn V., Bochar I. The study of technologies to improve physical-mechanical and chemical properties of reaction sintered ceramic materials on the basis of silicon carbide. Scientific Journal of TNTU. 2017. Vol. 86. No. 2. P. 14-20.

3. Van Kampen, Stochastic N. G. Processes in Chemistry and Physics. Norwell: Elsevier, 1992. 480 p.

4. Vamoş C., Suciua N., Vereecken H. Generalized random walk algorithm for the numerical modeling of complex diffusion processes. Journal of Computational Physics. 2003. Vol. 186 (2). P. 527-544. DOI: https://doi.org/10.1016/S0021-9991(03)00073-1

5. LaBolle E. M., Quastel J., Fogg E. G., Gravner J. Diffusion processes in composite porous media and their numerical integration by random walks: Generalized stochastic differential equations with discontinuous coefficients. Water Resources Research. 2000. Vol. 36 (3). P. 651-662. DOI: https://doi.org/10.1029/1999WR900224

6. Yong Y., Lou X., Li S., Yang C., Yin X. Direct simulation of the influence of the pore structure on the diffusion process in porous media. Computers \& Mathematics with Applications. 2014. Vol. 67 (2). P. $412-$ 423. DOI: https://doi.org/10.1016/j.camwa.2013.08.032

7. Hlushkou V., Khirevich S., Apanasovich V. V., Tallarek U. Pore-scale dispersion in electrokinetic flow through a random sphere packing. Analytical Chemistry. 2007. 79. P. 113-121. DOI: https://doi.org/10.1021/ac061168r

8. Chaplia Y., Chernukha O. Three-dimensional diffusion in a multiphase body with randomly disposed inclusions of a spherical form. International Journal of Heat and Mass Transfer. 2003. Vol. 46. P. 33233328. DOI: https://doi.org/10.1016/S0017-9310(03)00123-6

9. Чапля С. Я., Чернуха О. Ю. Фізико-математичне моделювання дифузійних процесів у випадкових і регулярних структурах. Київ: Наукова думка, 2009. 302 с.

10. Чернуха О. Ю., Білущак Ю. І., Чучвара А. С. Моделювання дифузійних процесів у стохастично неоднорідних структурах. Львів: Растр-7, 2016. 262 с.

11. Gyarmati J. Non-equilibrium Thermodynamics. Field Theory and Variational Principles. Berlin: Springer, 1970. 184 p. DOI: https://doi.org/10.1007/978-3-642-51067-0

12. Münster, A. Classical Thermodynamics. Wiley Interscience, 1970. 387 p.

13. Чернуха О., Чучвара А. Моделювання дифузії домішкової речовини у пористому тілі з випадковими сферичними порами при сумірних об'ємних частках фаз. Мат. методи та фіз.-мех. поля. 2019. 62. № 1. C. 150-161.

14. Рытов С. М., Кравцов Ю. А., Татарський В. И. Введение в статистическую радиофизику. Ч. II. Случайные поля. Москва: Наука, 1978. 464 с. 
15. Справочник по специальным функциям / под ред. М. Абрамовица и И. Стиган. М.: Мир, 1979. $830 \mathrm{c}$.

16. Лыков А. В. Теория теплопроводности. Москва: Высшая школа, 1978. 480 с.

УДК 517.958:532.72

\title{
МАТЕМАТИЧНЕ МОДЕЛЮВАННЯ ДИФУЗІЇ ДОМІШКОВИХ ЧАСТИНОК У СМУЗІ З ВИПАДКОВО РОЗТАШОВАНИМИ КУЛЬОВИМИ ВКЛЮЧЕННЯМИ РІЗНИХ МАТЕРІАЛІВ ЗА СПІВВИМІРНИХ ОБ'ЄМНИХ ЧАСТОК ФАЗ
}

\author{
Ольга Чернуха ${ }^{1,2}$; Юрій Білущак ${ }^{1,2}$; Анастасія Чучвара ${ }^{1}$
}

\author{
${ }^{1}$ Центр математичного моделювання Інституту прикладних проблем \\ механіки і математики імені Я. С. Підстригача НАН Украӥни, \\ Львів, Україна \\ ${ }^{2}$ Національний університет «Львівська політехніка», Львів, Украӥна
}

Резюме. Досліджено дифузію домішкових частинок у багатофазному випадково неоднорідному тілі з кульовими включеннями різних матеріалів за умови співвимірних об'ємних часток фаз. За теорією бінарних систем побудовано математичну модель дифузї домішки у багатофаззому тілі зі сферичними випадково розташованими включеннями різних радіусів. Для моделювання скелета тіла використано щільну упаковку куль різного радіуса. 3 використанням апарату теорії узагальнених функиій отримано диференціальне рівняння масоперенесення для тіла в цілому, яке враховує стрибок шуканої функиії та ї̈ похідної на випадкових гранииях поділу фаз. Трактуючи неоднорідність структури тіла як внутрішні джерела, отриманій крайовій задачі поставлено у відповідність еквівалентне інтегро-диференціальне рівняння. Розв'язок иього рівняння знайдено у вигляді інтегрального ряду Неймана розкладом в околі розв'язку однорідної крайової задачі з усередненими характеристиками середовища. Проведено процедуру усереднення за ансамблем конфігурацій фаз з рівномірною функиією розподілу та отримано формулу для визначення усередненого за ансамблем конфігурацій фаз поля конщентрачії мігруючої речовини у шарі з випадково розташованими кулями різних фізичних характеристик (фаз) з різними характерними радіусами за умови рівномірного розподілу включень в діляниі тіла. На основі отриманої розрахункової формули проведено кількісне дослідження масоперенесення домішки у тілі з кульовими включеннями, які заповнені матеріалами принципово різної фізичної природи, але співвимірних об'ємних часток. Також досліджено вплив щільності упаковки скелета кулями різного радіуса на усереднену концентрачію мігруючої речовини. Показано, що у випадку моделювання скелета тіла кулями одного радіуса значення усередненої концентрації мігруючої речовини для характерного радіуса, що є середньою величиною радіусів включень; радіуса, що відповідає найменшому кульовому включенню і радіуса на порядок меншого від чієї величини, співпадають.

Ключові слова: математичне моделювання, багатофазна випадкова структура, кульове включення, концентрація домішки, щілььна упаковка кулями, усереднення за ансамблем конфігурацій фаз, обчислення. 